\title{
Educação em espaços não formais: química e geografia - da sala de aula para o museu de solos de Roraima
}

\section{Education in non-formal spaces: chemistry and geography - from the classroom to the soil museum of Roraima}

Dilce dos Santos Alves (dilcealves@ hotmail.com)

(UERR - Universidade Estadual de Roraima)

Francisleile Lima Nascimento (leile_lima@ @otmail.com)

(UFRR - Universidade Federal de Roraima)

Márcia Teixeira Falcão (marciafalcao.geog@uerr.edu.br)

(UERR - Universidade Estadual de Roraima

Régia Chacon Pessoa de Lima (regiachacon13@gmail.com)

(UERR - Universidade Estadual de Roraima)

Resumo: O presente artigo aborda o ensino da química e geografia sob a ótica dos espaços não formais de ensino refletindo sobre o processo de ensino e de aprendizagem da química e geografia no contexto da educação não formal na perspectiva de relacionar teoria com prática no Museu de solos de Roraima. O objetivo do trabalho é analisar o Museu de solos em Roraima como um espaço não formal de educação para o ensino de geografia e química. Dessa forma, a pesquisa faz uma abordagem sobre a terminologia da educação formal e não formal, refletindo sobre o uso do Museu de Solos em Roraima no desenvolvimento de aulas alternativas de Química e Geografia. A metodologia parte de uma revisão bibliográfica caracterizada como descritiva, e qualitativa, sob uma abordagem metodológica sistêmica, de caráter exploratório, pois busca analisar a aula de campo para o ensino de geografia, tendo como foco Museu de solos de Roraima. A mensuração dos resultados parte do método qualitativo e análise de conteúdo. Sendo assim a pesquisa mostra a importância de valorização pelo ensino no sentido de promover novas metodologias e material didático que auxilie o docente no desenvolvimento da prática do ensino da química e da geografia. Dessa forma, a pesquisa propõe o desafio de trabalhar de maneira alternativa associando teoria e prática com uma proposta de intercalar a sala de aula com os espaços não formais como o Museu de solo de Roraima.

Palavras-chave: Educação Formal e Não formal; Geografia; Museu de Solos de Roraima; Química.

Abstract: This article addresses the teaching of chemistry and geography from the perspective of non-formal teaching spaces, reflecting on the teaching and learning 
process of chemistry and geography in the context of non-formal education in the perspective of relating theory to practice in the Soil Museum of Roraima. The objective of the work is to present and discuss the role of the Soil Museum in Roraima as a nonformal educational space for teaching geography and chemistry. In this way, the research approaches the terminology of formal and non-formal education, reflecting on the importance of Chemistry and Geography classes at the Soil Museum in Roraima. The methodology starts from a bibliographic review characterized as descriptive, and qualitative, under a systemic methodological approach, of an exploratory character, as it seeks to analyze the field class for teaching geography, focusing on the Soil Museum of Roraima. The measurement of results is based on the qualitative method and content analysis. Therefore, the research shows that there must be an appreciation for teaching in order to promote new methodologies and didactic material that helps the teacher in the development of the practice of teaching chemistry and geography. In this way, the research proposes the challenge of working in a different and playful way, alternating the classroom with non-formal spaces such as the Museum of Roraima solo.

Keywords: Formal and Non-formal Education; Geography; Soil Museum of Roraima; Chemistry.

\section{INTRODUÇÃO}

Considerando o contexto atual da educação brasileira percebe-se que as modernas atividades educacionais clamam por mudanças de valores, atitudes e responsabilidades que possam corresponder com o processo de ensino e de aprendizagem frente a vários obstáculos pelos quais a educação vem passando. Tais obstáculos referem-se à inovação e estratégias metodológicas proposta pela Base Nacional Comum Curricular (BNCC) que visa integrar as diversas áreas do conhecimento com as novas tecnologias educacionais e com as aulas diferenciadas já utilizadas (como aula de campo, visita técnica, aulas expedições entre outras), que instiguem o aprendizado.

Nessa perspectiva, surge a metodologia do uso dos espaços não formais de ensino como as praças, áreas verdes, teatro, parques ecológicos, museus entre outros, que são espaços que proporcionam educação e o desenvolvimento da ciência e cultura. Esses espaços são regulamentados e constituídos de infraestrutura técnica e que disponibilizam atividades programadas e executadas para esses fins educativos (JACOBUCCI, 2008).

Partindo desse princípio, a presente pesquisa tem como objetivo analisar a viabilidade do Museu de solos em Roraima como espaço não formal de educação para o ensino da geografia e da química. Dessa forma, foram desenvolvidos os seguintes objetivos específicos: Analisar por meio da pesquisa bibliográfica a terminologia da educação formal e não formal; refletir sobre o museu como espaço não formal de 
ensino; Analisar a importância de desenvolver as aulas diferenciadas de química e de geografia em espaços não formal de ensino como o Museu de Solos de Roraima.

A metodologia da pesquisa parte de uma revisão bibliográfica caracterizada como descritiva, e qualitativa, sob uma abordagem metodológica sistêmica, de caráter exploratório, pois busca analisar a aula de campo para o ensino de geografia e química, tendo como objeto de estudo o Museu de solos de Roraima. A mensuração dos resultados parte do método qualitativo e análise de conteúdo.

Sendo assim, a pesquisa encontra-se dividida em tópicos. $\mathrm{O}$ primeiro corresponde a introdução que apresenta a temática, os objetivos, e a metodologia aplicada. O segundo reflete sobre a educação formal e não formal abordando os principais conceitos e terminologia, bem como o museu como espaço não formal de ensino. O terceiro trata-se da metodologia apresentando os procedimentos e métodos da pesquisa. $\mathrm{O}$ quarto refere-se a análise e discussão dos resultados, onde é apresentado o Museu de solos de Roraima com sua respectiva localização geográfica, e caracterização dos aspectos históricos e físicos do museu; além da reflexão da disciplina de química, sua breve contextualização com a base nacional comum curricular (BNCC), e a importância das aulas de química no Museu de solos em Roraima; apresenta-se também a disciplina de geografia, uma breve discussão da disciplina na base nacional comum curricular (BNCC), e a importância das aulas de geografia no Museu de solos em Roraima; por fim são discorrido as considerações finais.

\section{EDUCAÇÃO FORMAL E NÃO FORMAL: CONCEITOS E TERMINOLOGIA}

Compreende-se como educação o processo de ensino-aprendizagem adquirida pelo indivíduo ao longo da vida. Esse processo de ensino pode ocorrer de três formas: educação escolar formal, educação informal, e educação não formal. A primeira diz respeito ao ensino desenvolvido no âmbito escolar; a segunda trata-se do ensino transmitido e repassado pelo convívio familiar e social; e a terceira é o ensino que ocorre fora do ambiente escolar, mas que tem a intenção de promover conhecimento como uma extensão da sala de aula (VIEIRA; BIANCONI; DIAS, 2005).

A educação não formal surgiu no amplo contexto educacional mencionado por Philip Coombs como um ensino fora do ambiente escolar. Esse termo ganha relevância no final da década de 1970, sendo alvo de diversas discussões acerca da crise educacional e da formulação de novos conceitos educacionais possibilitando a quebra 
de paradigmas favorecendo o contexto educacional das aulas teóricas e práticas fora da sala de aula, compreendida mais tarde como educação não formal (GARCIA, 2007).

Conforme Ramos (2019), a educação não formal surgiu no contexto de uma série de críticas no sistema educacional relacionada ao campo pedagógico, onde o universo escolar e a família se encontram impossibilitados de representar todas as demandas sociais que lhes são cabíveis, impostas ou ainda desejadas.

Quanto à base conceitual pode-se compreender a educação não formal como atividades de caráter intencional voltada às organizações políticas, profissionais, científicas, culturais, agências formativas para grupos sociais, educação cívica, entre outros que visam um ensino em espaço fora do ambiente escolar ou familiar (LIBÂNEO, 2002).

Nessa perspectiva, a educação não formal é aquela ofertada em espaços como museus, centros de ciências, ou qualquer outro espaço que proporcione a aprendizagem de conteúdos da escolarização formal planejada de forma objetiva e bem direcionada ao processo de ensino-aprendizagem podendo ser desenvolvidos a partir de oficinas artesanais, culturais, esportivas e recreativas (VIEIRA; BIANCONI; DIAS, 2005).

Sendo assim, a educação não formal pode ocorrer em ambientes fora da escola, em organizações sociais, movimentos não governamentais (ONGs) e outras entidades filantrópicas atuantes na área social que abordam processos educativos (GOHN, 2008).

\subsection{MUSEU COMO ESPAÇO NÃO FORMAL DE ENSINO}

Para compreendermos o museu como um espaço não formal de ensino é importante considerar que o este se enquadra dentro dos espaços onde a educação não formal se desenvolve para proporcionar a aprendizagem de conteúdos da escolarização formal (VIEIRA; BIANCONI; DIAS, 2005).

De acordo com Gaspar (1993, p. 12), o termo museu vem do latim "museum" que por sua vez se origina do grego "mouseion", denominação, na antiga Grécia, do templo ou santuário das musas.

Conforme Falcão $(2009,21)$ o museu é um espaço que adquire, conserva, investiga, difunde e expõe os testemunhos materiais do homem e de seu entorno, para educação e deleite da sociedade. Enquanto instituição, o museu é considerado como um "Espaço permanente, sem fins lucrativos, a serviço da sociedade e do seu desenvolvimento, aberta ao público". Logo, o museu se estabelece como um espaço para a educação não formal. 
Partindo desse princípio, se pode compreender que o museu apresenta diversas especificidades ou objetos a serem estudados: as coleções, os acervos, o espaço expositivo e o circuito expositivo, a reserva técnica, dentre outros. Dessa forma, os museus e centros culturais têm sua existência vinculada à ideia de que é importante oferecer ao público experiências e uma relação diferenciada com o universo do saber, da cultura e do conhecimento humano (BITTER, 2009). Nessa perspectiva, Fronza-Martins (2015) menciona que:

\begin{abstract}
A questão da educação em museus possui um importante foco de interesse na atualidade, tanto no que diz respeito ao seu papel social, quanto no que se refere às práticas realizadas nesse espaço e suas possíveis reflexões. Percebese o interesse não apenas na organização e preservação de acervos, mas também na ênfase da compreensão, desenvolvimento e promoção da divulgação, bem como na formação de público como forma de disseminar conhecimentos por meio de uma ação educativa (FRONZA-MARTINS, 2015, p. 71).
\end{abstract}

Sendo assim, os museus podem ser constituídos em torno de temáticas extremamente variadas, cobrindo uma vasta área da produção humana. Podendo ser explorado como uma extensão da sala de aula na concepção do ensino em espaço não formal, no qual os alunos possam se identificar e ter maior liberdade para aprender associar novos conhecimentos ao ensino tradicional (BITTER, 2009).

Corroborando, com esse viés Brandão (2004, p. 9) ressalta que "não há uma forma única nem um único modelo de educação; a escola não é o único lugar onde ela acontece e talvez nem seja o melhor; o ensino escolar não é a sua única prática e o professor profissional não é o seu único praticante." Dessa forma, os espaços não formais como o museu, tornam-se uma saída para os docentes proporcionarem um ensino mais prazeroso e atrativo aos alunos associado ao processo de aprendizagem dos conteúdos da escolarização formal (HENDGE, 2019).

É importante frisar segundo Bitter (2009) que desde o início, os museus sempre se configuravam como espaços de pesquisa e ensino, por isso os mesmos apresentam um caráter educacional vinculado à sua própria origem, que difunde muita informação e conhecimento em seus objetos de exposições. Sendo assim, o aluno ao ter contato com esses objetos expostos pode ter contato com partes, fragmentos ou vestígios dessas realidades, construindo e reconstruído suas concepções e conceitos.

\title{
5 FERRAMENTAS E PROCEDIMENTOS METODOLÓGICOS
}


A pesquisa se desenvolveu com base em uma leitura multidisciplinar comandada principalmente pelas fundamentações teóricas de (VIEIRA; BIANCONI; DIAS, 2005; RAMOS, 2019; LIBÂNEO, 2002; GASPAR, 1993; FALCÃO, 2009; BITTER, 2009; FRONZA-MARTINS, 2015) com intuito de analisar o contexto da educação formal e não formal, bem como o ensino da geografia e química, tendo como direcionamento o museu como espaço educacional de ensino não formal.

Partindo desse princípio, a pesquisa parte de um estudo bibliográfico, do ponto de vista dos procedimentos técnicos, elaborado a partir de material já publicado, constituído principalmente de livros, artigos de periódicos e material disponibilizado na Internet (GIL, 2008).

Do ponto de vista dos métodos de abordagem, a presente pesquisa faz uso do método descritivo, para a descrição das características de determinada população ou fenômeno; do método experimental, para realizar interpretações e avaliações na aplicação de determinados fatores, ou simplesmente dos resultados já existentes dos fenômenos (MARCONI; LAKATOS, 2011).

A pesquisa foi direcionada para as disciplinas de Geografia e Química aos alunos do 1 ano do Ensino Médio da Escola Estadual Presidente Tancredo Neves, na qual foi realizada uma visita técnica com 25 alunos ao museu de solos de Roraima, localizado na cidade de Boa Vista, onde o curador e professor doutor José Frutuoso do Vale Junior, discorre em uma palestra sobre solos e as possíveis relações, envolvendo assuntos discutidos nas disciplinas de Geografia e Química, como por exemplo, a importância dos componentes químicos para cada tipo de solo e suas transformações a partir do revelo, clima e bioma. O curador ressaltou ainda a importância da preservação do solo para a manutenção da vida na terra, sem deixar de destacar a importância do museu de solos como sendo um espaço não formal de ensino que proporciona conhecimento científico ao alcance da comunidade geral.

Sendo assim, a pesquisa fez ainda uso do método exploratório, para proporcionar maior familiaridade com o problema por meio do levantamento bibliográfico, e do método qualitativo para verificar a relação da realidade com o objeto de estudo (RAMOS; RAMOS; BUSNELLO, 2005). Faz o uso da análise de conteúdo para obtenção dos resultados. Segundo Bardin (2011) a análise de conteúdo designa a técnica de investigar e interpretar de forma sistematizada os dados coletados, obtendo várias interpretações de uma análise indutiva por parte do pesquisador, sendo assim, a 
análise de conteúdo possibilita diferentes modos de conduzir o processo de interpretação.

\section{ANÁLISE E DISCUSSÃO DOS RESULTADOS}

\subsection{MUSEU DE SOLOS DE RORAIMA}

\subsubsection{Localização geográfica do Museu de Solos de Roraima}

O Museu de Solos do Estado de Roraima, localizado no Campus do Cauamé Universidade Federal de Roraima - BR 174 - KM 12. O local abriga amostras de rochas, de minerais, além de estar aberto para visitas agendadas de escolas (públicas e privadas) do ensino fundamental, médio, instituições de ensino superior e demais instituições interessadas, ver na Figura 01.

Figura 01 - Localização Geográfica do Museu de Solos em Roraima

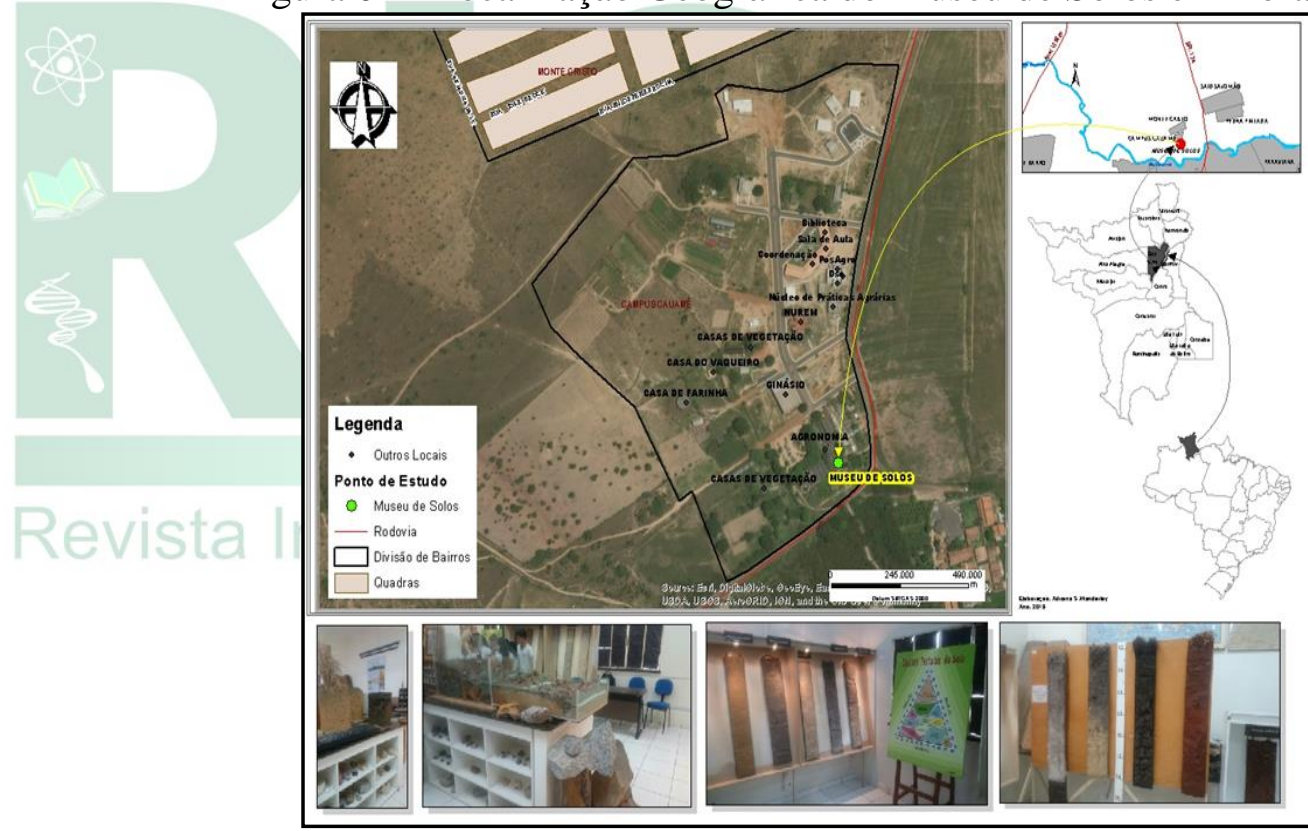

Fonte: mapa produzido por Adriana de Souza Wanderley. (2019)

\subsubsection{Caracterização dos Aspectos Históricos e Físicos do Museu de Solos em}

\section{Roraima}

O Museu de Solos do Estado de Roraima pertence a Universidade Federal de Roraima (UFRR), e está localizado no Centro de Ciências Agrárias, no campus do Cauamé. Este começou a ser estruturado em 2011, a partir da organização de amostras coletadas de minerais, rochas e solos de alguns dos municípios do estado, mas efetivamente o museu só foi inaugurado no ano de 2013 (UFRR, 2019). 
De acordo com seu idealizador o professor curador do museu Dr. José Frutuoso do Vale Júnior, a criação do museu tem como objetivo facilitar o contato dos alunos e da comunidade geral com o solo, com o intuito de sensibilizar a comunidade de que o solo é um componente imprescindível no meio ambiente, que é fundamental para a existência da vida, e que precisa ser preservado da degradação, além de dar suporte para aulas de algumas disciplinas do curso de Graduação e Pós-graduação em Agronomia (UFRR, 2019), ver na Figura 02.

Figura 02 - Tipos de solo: Museu de Solos em Roraima

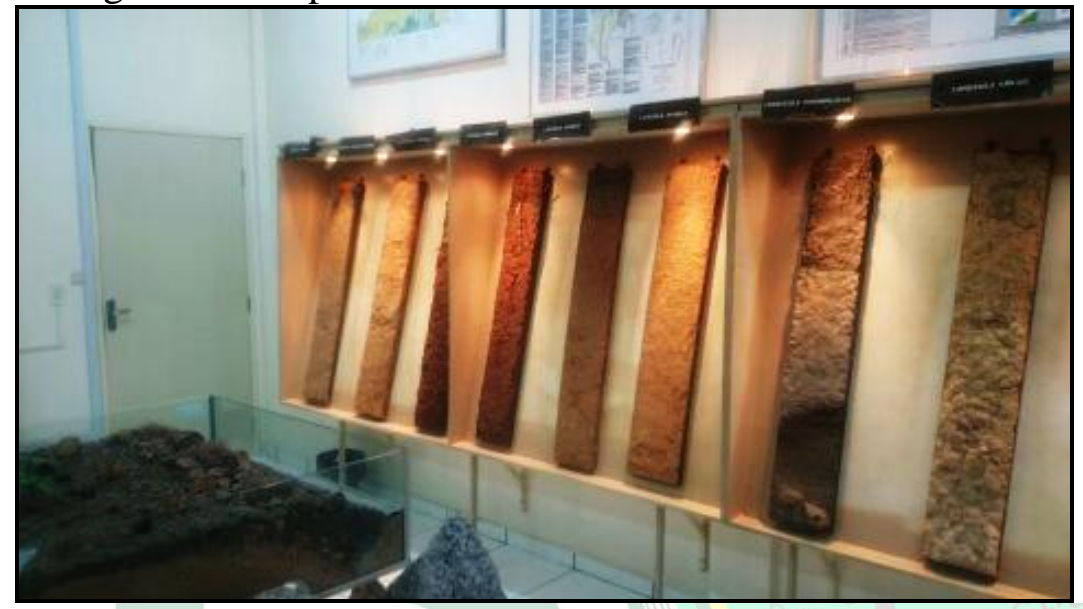

Fonte: fotografia de arquivo pessoal (2019).

O Museu de Solos de Roraima está entre os quatro mais estruturados do Brasil, juntamente com o Museu da Universidade Federal de Santa Maria Rio Grande do Sul, o Museu de Solos do Brasil que fica na Universidade Rural Rio Janeiro e o Museu de Ciências da Terra Alexis Dorofeef, que fica localizado em Viçosa -Minas Gerais (UFRR, 2019).

Atualmente o museu tem em seu acervo cerca 30 (trinta) monólitos que representam 12 (doze) tipos de solos catalogados em Roraima. O termo monólito é utilizado para denominar cortes verticais de solos coletados e preservados com produtos específicos, em laboratórios ou museus (MARQUES et al., 2011). Os monólitos são utilizados para facilitar o estudo das características morfológicas do solo, e são confeccionados de acordo com normas do Sistema Brasileiro de Classificação do Solo, ver na Figura 03.

Figura 03 - Monólito e cortes verticais: Museu de Solos em Roraima 

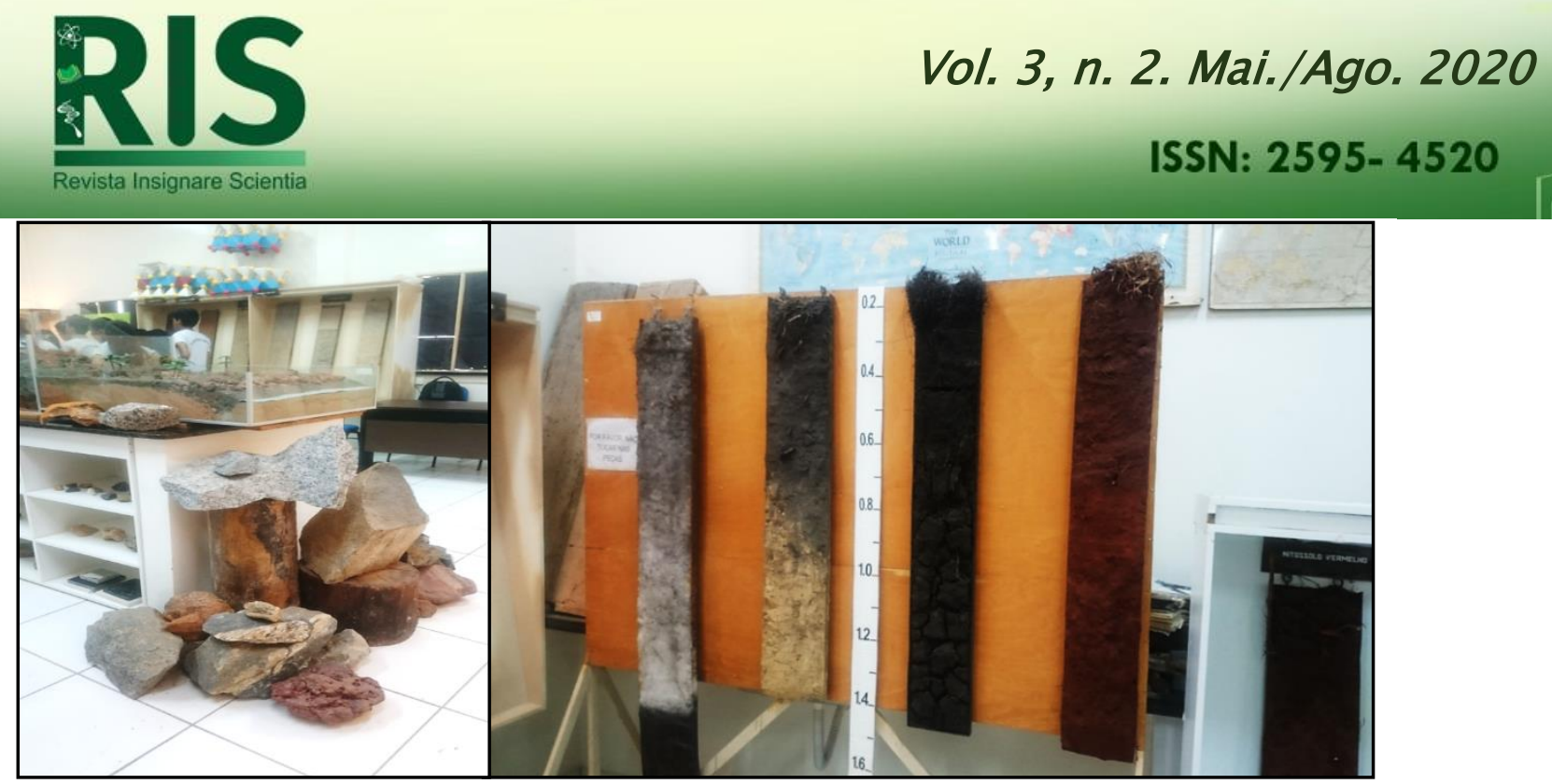

Fonte: fotografias de arquivo pessoal (2019).

O museu de solos recebe em média cerca de 700 (setecentas) visitas de estudantes anualmente oriundos das instituições de ensino de nível médio, técnico e superior, são visitas assistidas e monitoradas pelos monitores do curso de agronomia e de iniciação científica. As visitas contribuem para o ensino como uma ferramenta importante e exercendo uma função de facilitador para a divulgação do conhecimento sobre a ciência do solo, além de ser um instrumento didático. Segundo o professor curador do museu, o Dr. José Frutuoso do Vale Júnior, o contato visual e sensorial é de estrema relevância para a elaboração das percepções sobre a morfologia dos solos (UFRR, 2019), ver na Figura 04.

Para Reigota (2010), tal assimilação rompe a concepção sobre um meio ambiente mais naturalístico e passa a dar ênfase as relações de reciprocidade entre a sociedade e a natureza, reconhecendo a importância dos aspectos históricos, sociais e culturais do meio ambiente.

Portanto, o museu de solos de Roraima como espaço não formal de ensino constitui-se um lugar de inserção social, que incentiva não só a construção do conhecimento científico, como também preceitos morais e posturas comprometidas com o meio ambiente, tento como papel fundamental a difusão do conhecimento científico, contribuindo para o avanço nos estudos sobre ciência do solo. Além de ser uma ferramenta didática pedagógica de grande relevância, auxiliando professores na expansão de conhecimento sobre solo, visando assim, mudanças de atitudes relacionadas ao meio ambiente (UFRR, 2019).

De acordo com Jacobucci (2008) a compreensão de espaço não formal seria os espaços diferentes da escola que promovem ou desenvolvem atividades educativas a exemplo os programas sociais e culturais, logo o museu de solos de Roraima de acordo 
com suas atribuições e aspecto de inserção social surge como esse espaço não formal que pode ser utilizado para o desenvolvimento de diversas atividade educativas que podem auxiliar nas aulas de geografia e química.

Figura 04 - Visita técnica de alunos: Museu de solos em Roraima

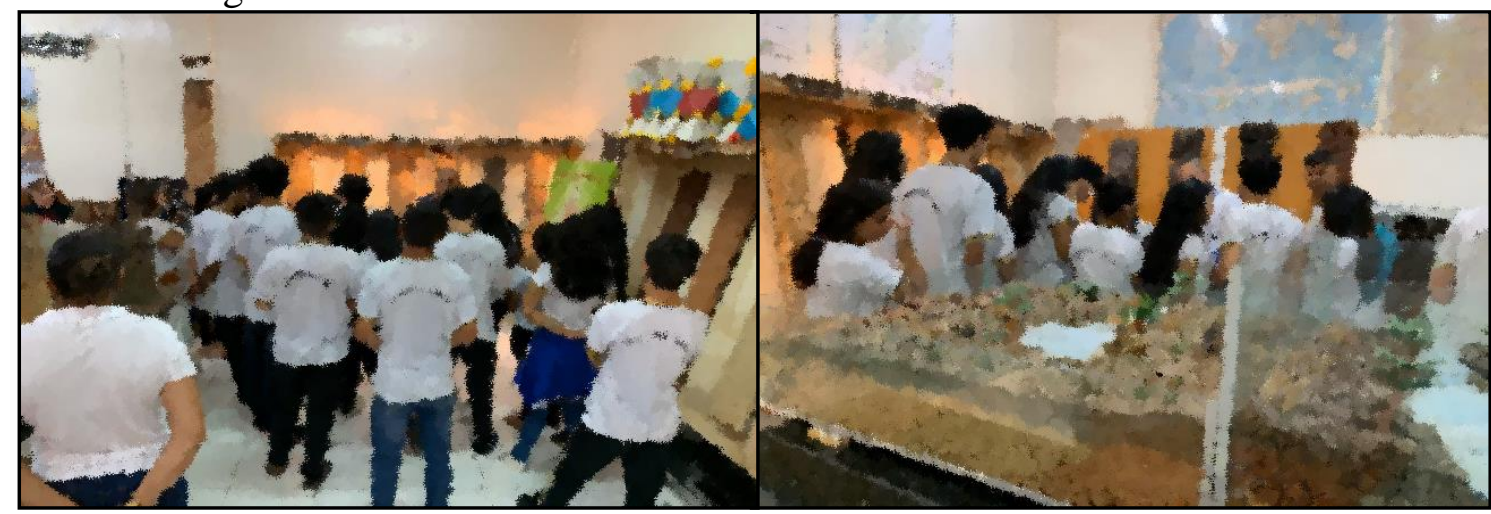

Fonte: fotografias de arquivo pessoal (2019).

\subsection{DISCIPLINA DE QUÍMICA}

\subsubsection{Breve Discussões da Base Nacional Comum Curricular (BNCC) na Disciplina} de Química

No que tange a disciplina de Química na BNCC, a mesma compreende a área de Ciências da Natureza e suas Tecnologias tendo como objetivo o comprometimento com a formação dos jovens para o enfrentamento dos desafios da contemporaneidade, na direção da educação integral e da formação cidadã. Tem como princípio levar o alunado a aprofundar o exercício do pensamento crítico e realizar novas leituras do mundo a partir de situações-problema, conforme as competências gerais das Ciências da Natureza e suas Tecnologias, que compreende a disciplina de química, ver no Quadro 01.

Quadro 01 - Competências Gerais das Ciências da Natureza e suas Tecnologias

COMPETÊNCIAS GERAIS
M1 - Compreender os elementos culturais que constituem as identidades.
M2 - Compreender a gênese e a transformação das diferentes organizações territoriais e os
múltiplos fatores que neles intervêm, como produto das relações de poder.
M3 - Compreender o desenvolvimento da sociedade como processo de ocupação de espaços físicos e
as relações da vida humana com a paisagem.
M4 - Compreender a produção e o papel histórico das instituições sociais, políticas e econômicas,
associando-as às práticas dos diferentes grupos e atores sociais.
M5 - Compreender e valorizar os fundamentos da cidadania e da democracia, favorecendo uma
atuação consciente do indivíduo na sociedade.

M6 - Perceber-se integrante e agente transformador do espaço geográfico, identificando seus 
elementos e interações.

M7 - Entender o impacto das técnicas e tecnologias associadas aos processos de produção, o desenvolvimento do conhecimento e a vida social.

M8 - Entender a importância das tecnologias contemporâneas de comunicação e informação e seu impacto na organização do trabalho e da vida pessoal e social.

M9 - Confrontar proposições a partir de situações históricas diferenciadas no tempo e no espaço e indagar sobre processos de transformações políticas, econômicas e sociais.

Fonte: elaborado a partir da BNCC (2019).

Nesse cenário, a BNCC propõe ampliar e sistematizar as aprendizagens essenciais, criando condições para que os alunos possam explorar os diferentes modos de pensar e de falar da cultura científica, situando-a como uma das formas de organização do conhecimento produzido em diferentes contextos históricos e sociais, possibilitando-lhes apropriar-se dessas linguagens específicas (VIANNA; RITTER, 2019).

A BNCC propõe ainda para a disciplina de química, o objetivo de analisar a ciclagem de elementos químicos no solo, na água, na atmosfera e nos seres vivos e interpretar os efeitos de fenômenos naturais e da interferência humana sobre esses ciclos, para promover ações individuais e/ou coletivas que minimizem consequências nocivas à vida (BNCC, 2018).

\subsubsection{Reflexões da Importância das Aulas de Química no Museu de Solos em}

\section{Roraima}

Nos últimos anos, percebe-se que as pesquisas voltadas para o Ensino de Ciências vêm buscando novas alternativas para melhorar o ensino, pesquisando novas formas ou as aprimorando para a melhoria da aprendizagem, sem estar limitado apenas ao espaço formal de educação. Com isso surgem os espaços não formais de educação, que são aliados, ou seja, são parceiros das escolas, potencializando assim, a aprendizagem (HENDGE, 2019). Dentre esses ambientes parceiros da escola, pode-se destacar os museus de ciências, pois são ferramentas de grande potencial para a contribuição da divulgação e popularização do conhecimento científico.

Para Marandino et al., (2008, p. 13) esses ambientes se caracterizam "como locais que possuem uma forma própria de desenvolver sua dimensão educativa, buscando diferenciá-los das experiências formais de educação, como aquelas desenvolvidas na escola e das experiências informais", além de ser um elemento motivacional para os alunos na realização das atividades, facilitando a aprendizagem. 
Portanto são espaços que se destacam por contribuir através da contextualização para a divulgação da educação em ciências.

Nesse contexto, Jacobucci (2008) concebe que esses ambientes que proporcionam o desenvolvimento da ciência e cultura, bem como o processo de ensino aprendizagem característicos dos espaços formais de educação merecem destaque no processo de construção do conhecimento, pois esses espaços não formais estão regulamentados de infraestruturas que possibilitam atividades programadas e executadas para esses fins educativos.

Considerando, que os museus são ambientes que possuem um papel de destaque para a divulgação científica e para a formação de conceitos científicos, Rocha; Vasconcelos (2016) ressaltam que seu uso pode ser relevante para se trabalhar conteúdos de química, tendo em vista que a disciplina pode ser comumente vinculada na mídia o vista por alguns alunos como enfadonha. Para Silva (2015), os museus de ciências apresentam um grande potencial para a divulgação do conceito químico e popularização da ciência Química, uma vez que é trabalhado de forma contextualizada, oportunizando um domínio popular dos saberes químicos, seja na alimentação, saúde ou em fatos simples do nosso cotidiano.

Diante disso, o Museu de solos de Roraima, configura-se como um espaço que propicia aprendizado de conteúdos de Química, já que o solo tem em sua composição substâncias como pH e sais e elementos químicos essências para a vida (VIANNA; RITTER, 2019). Sendo assim, este espaço pode ser utilizado como uma ferramenta alternativa no ensino da Química. Além de ser um ambiente em que os alunos aprendem de forma descontraída, pois é um lugar que apresenta conhecimento de forma visual e sensorial, onde os estudantes podem associar os seus conhecimentos prévios adquiridos na sala de aula, com outros campos do conhecimento para então ganhar significado.

\subsection{DISCIPLINA DE GEOGRAFIA}

\subsubsection{Breve Discussões da Base Nacional Comum Curricular (BNCC) na Disciplina} de Geografia

A BNCC na área de Ciências Humanas e Sociais Aplicadas integra as disciplinas de (Filosofia, Geografia, História e Sociologia) propõe a ampliação e o aprofundamento conceitual, desenvolvimento das capacidades de observação, memória e abstração que permitam uma percepção mais acuradas da realidade, e raciocínios mais 
complexos, além de um domínio maior sobre diferentes linguagens, no sentido de favorecer os processos de simbolização e de abstração.

Dessa forma, a BNCC visa com a disciplina de geografia o desenvolvimento das habilidades cognitivas do aluno como: ler, interpretar, comparar e analisar textos de diferentes fontes e linguagens e informações gráficas e cartográficas; classificar, organizar e relacionar dados e informações; estabelecer propostas de intervenção e transformações na sociedade e no espaço; observar e analisar situações, acontecimentos, fenômenos e processos em seu espaço de vivência; utilizar os métodos necessários para a realização de pesquisas, bem como generalizar conceitos, aplicá-los, constituí-los e, principalmente, relacioná-los entre si. Esses objetivos tendem a responder as competências e habilidades da disciplina para melhor desenvolvimento da capacidade dos alunos, ver no Quadro 02.

Quadro 02 - Competências Gerais das Ciências Humanas e Sociais Aplicadas (Geografia)

\section{COMPETÊNCIAS E HABILIDADES}

\section{$1^{\circ}$ ANO}

1. Analisar processos políticos, econômicos, sociais, ambientais e culturais nos âmbitos local, regional, nacional e mundial em diferentes tempos, a partir de procedimentos epistemológicos e científicos, de modo a compreender e posicionar-se criticamente com relação a esses processos e às possíveis relações entre eles.

2. Analisar a formação de territórios e fronteiras em diferentes tempos e espaços, mediante a compreensão dos processos sociais, políticos, econômicos e culturais geradores de conflito e negociação, desigualdade e igualdade, exclusão e inclusão e de situações que envolvam o exercício arbitrário do poder.

3. Contextualizar, analisar e avaliar criticamente as relações das sociedades com a natureza e seus impactos econômicos e socioambientais, com vistas à proposição de soluções que respeitem e promovam a consciência e a ética socioambiental e o consumo responsável em âmbito local, regional, nacional e global.

4. Analisar as relações de produção, capital e trabalho em diferentes territórios, contextos e culturas, discutindo o papel dessas relações na construção, consolidação e transformação das sociedades.

5. Reconhecer e combater as diversas formas de desigualdade e violência, adotando princípios éticos, democráticos, inclusivos e solidários, e respeitando os Direitos Humanos.

6. Participar, pessoal e coletivamente, do debate público de forma consciente e qualificada, respeitando diferentes posições, com vistas a possibilitar escolhas alinhadas ao exercício da cidadania e ao seu projeto de vida, com liberdade, autonomia, consciência crítica e responsabilidade.

\section{$2^{\circ}$ ANO}

1. Analisar processos políticos, econômicos, sociais, ambientais e culturais nos âmbitos local, regional, nacional e mundial em diferentes tempos, a partir de procedimentos epistemológicos e científicos, de modo a compreender e posicionar-se criticamente com relação a esses processos e às possíveis relações entre eles. 
2. Analisar a formação de territórios e fronteiras em diferentes tempos e espaços, mediante a compreensão dos processos sociais, políticos, econômicos e culturais geradores de conflito e negociação, desigualdade e igualdade, exclusão e inclusão e de situações que envolvam o exercício arbitrário do poder.

3. Contextualizar, analisar e avaliar criticamente as relações das sociedades com a natureza e seus impactos econômicos e socioambientais, com vistas à proposição de soluções que respeitem e promovam a consciência e a ética socioambiental e o consumo responsável em âmbito local, regional, nacional e global.

4. Analisar as relações de produção, capital e trabalho em diferentes territórios, contextos e culturas, discutindo o papel dessas relações na construção, consolidação e transformação das sociedades.

5. Reconhecer e combater as diversas formas de desigualdade e violência, adotando princípios éticos, democráticos, inclusivos e solidários, e respeitando os Direitos Humanos.

6. Participar, pessoal e coletivamente, do debate público de forma consciente e qualificada, respeitando diferentes posições, com vistas a possibilitar escolhas alinhadas ao exercício da cidadania e ao seu projeto de vida, com liberdade, autonomia, consciência crítica e responsabilidade.

\section{$3^{\circ}$ ANO}

1. Analisar processos políticos, econômicos, sociais, ambientais e culturais nos âmbitos local, regional, nacional e mundial em diferentes tempos, a partir de procedimentos epistemológicos e científicos, de modo a compreender e posicionar-se criticamente com relação a esses processos e às possíveis relações entre eles.

2. Analisar a formação de territórios e fronteiras em diferentes tempos e espaços, mediante a compreensão dos processos sociais, políticos, econômicos e culturais geradores de conflito e negociação, desigualdade e igualdade, exclusão e inclusão e de situações que envolvam o exercício arbitrário do poder.

3. Contextualizar, analisar e avaliar criticamente as relações das sociedades com a natureza e seus impactos econômicos e socioambientais, com vistas à proposição de soluções que respeitem e promovam a consciência e a ética socioambiental e o consumo responsável em âmbito local, regional, nacional e global.

4. Analisar as relações de produção, capital e trabalho em diferentes territórios, contextos e culturas, discutindo o papel dessas relações na construção, consolidação e transformação das sociedades.

5. Reconhecer e combater as diversas formas de desigualdade e violência, adotando princípios éticos, democráticos, inclusivos e solidários, e respeitando os Direitos Humanos.

6. Participar, pessoal e coletivamente, do debate público de forma consciente e qualificada, respeitando diferentes posições, com vistas a possibilitar escolhas alinhadas ao exercício da cidadania e ao seu projeto de vida, com liberdade, autonomia, consciência crítica e responsabilidade.

Fonte: elaborado a partir da BNCC (2019).

A BNCC propõe ainda para a disciplina de geografia a Utilização das linguagens cartográfica, gráfica e iconográfica e de diferentes gêneros textuais e as tecnologias digitais de informação e comunicação de forma crítica, significativa, reflexiva e ética nas diversas práticas sociais (incluindo as escolares) para se comunicar, acessar e disseminar informações, produzir conhecimentos, resolver problemas e exercer protagonismo e autoria na vida pessoal e coletiva. 


\subsubsection{Reflexões da Importância das Aulas de Geografia no Museu de Solos em}

\section{Roraima}

Considerando o Museu de solos de Roraima, como um espaço não formal de ensino que constitui os aspectos, histórico, sociais, políticos e culturais da sociedade, bem como a preservação do meio ambiente. Jacobucci (2008) menciona que o uso de espaços não formais estimula a saída do aluno ao campo de estudo e revela ao mesmo tempo um universo antes não percebido pelos discentes como espaço de educação levando o ensino a outra dimensão promovendo a inserção social e o processo de interação da teoria e prática. Logo, a aula de campo nos espaços não formais de ensino surge como a metodologia que proporcionada a saída do alunado da sala de aula do contexto teórico para o contato com o objeto de estudo e a prática científica.

Nesse sentido, Sousa et al., (2016) afirmam que a aula de campo desperta a mente e a capacidade de aprender, valorizando os espaços fora da sala de aula considerados como espaços estimulantes e relevante cenário para a aprendizagem que se propaga também como um aumento de afeto e confiança entre discentes e docentes.

Dessa forma, se o museu se constitui em um lugar de inserção social, que incentiva não só a construção do conhecimento científico, como também preceitos morais e posturas comprometidas com o meio ambiente. A aula de campo possibilita exatamente esse processo de inserção social levando o aluno para um ambiente de estudo fora dos muros burocráticos da sala de aula. Entretanto, por mais que essa metodologia seja um instrumento pedagógico eficiente e bastante proveitoso na relação ensino-aprendizagem, a mesma não deve ser utilizada sem fundamentação prévia, tendo em vista que sua função principal é a materialização da teoria (CARBONELL, 2002).

Corroborando Passini (2007, p. 172-176), menciona que "a aula de campo seria um método ativo e interativo, pois o espaço não é fragmentado. Ele é a sala de aula, o pátio da escola, o refeitório, o corredor, a rua do colégio, a casa do aluno, o bairro, a cidade, o município, o parque florestal, o fundo de vale, entre outros". Logo, a aula de campo tem papel fundamental na difusão do conhecimento científico, e quando se trata de espaço não formal de ensino como o museu (objeto de estudo) pode contribuir positivamente para o avanço nos estudos sobre ciência do solo.

Para Libâneo (1994, p. 71), quando se trata de desenvolver o processo de ensino aprendizagem "todos esses procedimentos que permitem uma discussão em 
torno do mundo concreto do aluno devem ser enriquecidos com visitas às localidades abordadas".

Como é o caso da aula de campo que por ser uma ferramenta didática pedagógica de grande relevância, auxiliando professores na expansão de conhecimento, visa a possibilidade de mudanças de atitudes relacionadas ao meio ambiente, pois tem uma forte tendência em desenvolver no aluno uma sensibilização maior ao mundo natural e cultural, além de propiciar o enriquecimento harmonioso da personalidade do aluno e a aquisição de conhecimentos de conteúdos relacionados à visita (SOUSA et al., 2016).

\section{CONSIDERAÇÕES FINAIS}

Diante do que foi apresentado referente ao uso dos espaços não formais para o ensino da geografia e da química percebe-se que a metodologia apresenta resultados significativos para o processo de ensino e de aprendizagem dos alunos, pois dinamiza a aula e proporcionando a busca por mais conhecimento, promovendo o protagonismo dos alunos nesse processo ensino.

Nota-se que a proposta de desenvolver aulas alternativas em espaço não formal de ensino como o museu como vai de encontro com a BNCC que no que tange as habilidades e competências de promover inovações ao ensino e criar novas estratégias metodológicas que integram as diversas áreas do conhecimento com a realidade do aluno.

Retornando ao objetivo de analisar a viabilidade do Museu de solos em Roraima como espaço não formal de educação para o ensino da geografia e da química percebe-se conforme propõe a BNCC que visa ampliar e sistematizar as aprendizagens essenciais, que o museu possibilita condições para que os alunos possam explorar os diferentes modos de pensar e de falar da cultura científica.

Logo, a pesquisa mostra que o museu apresenta diversas especificidades ou objetos que podem ser analisados em estudos tanto pela disciplina de química, quanto de geografia, pois a instituição disponibiliza uma grande coleção, acervos, espaço e circuito expositivo, e reserva técnica, que podem ser explorados no processo de conciliar teoria e prática, oferecendo aos alunos e acadêmicos, experiências e uma relação diferenciada com o universo do saber, da cultura e do conhecimento humano.

Quanto ao objetivo de analisar por meio da pesquisa bibliográfica a terminologia da educação formal e não formal, fica evidente que a educação conforme 
as literaturas pesquisadas, ocorre em três ambientes diferentes, classificadas como formal que ocorre dentro do âmbito escolar, a informal compreendida como ensino transmitido no seio familiar e social, e o não formal, aquele que ocorre em ambiente não escolares como teatro, museus, jardim botânicos, zoológicos, parques nacionais, entre outros.

No que se refere ao objetivo de refletir sobre o Museu de Solos em Roraima como espaço não formal de ensino, a pesquisa mostra que o Museu já vem sendo explorado como espaço não formal de ensino, recebendo anualmente cerca de 700 visitas de estudantes das instituições de ensino de nível médio, técnico e superior.

Quando se trata de elucidar sobre a importância das aulas de Química no Museu de Solos em Roraima, a pesquisa mostra que o Museu como espaço não formal de ensino tem contribuído para ensino como uma ferramenta importante e exercendo uma função como facilitador para a divulgação do conhecimento sobre a ciência do solo, além de ser um instrumento didático para diversas áreas do conhecimento, principalmente em química quando se busca analisar a ciclagem de elementos químicos no solo.

No que tange, analisar a importância de desenvolver as aulas diferenciadas de química e de geografia em espaços não formal de ensino como o Museu de Solos de Roraima, a pesquisa mostra que o Museu proporciona um grande acervo de material para desenvolvimento de diversos conteúdos do ensino fundamental ensino médio, ensino superior, bem como para as especializações na área da geografia. Dessa forma, o museu constitui em um lugar de inserção social, que incentiva não só a construção do conhecimento científico, como também preceitos morais e posturas comprometidas com o meio ambiente, sendo para a disciplina de geografia um espaço não formal de ensino favorável para a análise de solo, minerais, vegetação e seus agentes modificadores.

Portanto esta pesquisa mostra a valorização que se deve dar pelo ensino no sentido de promover novas metodologias e material didático que auxilie o docente no desenvolvimento da prática do ensino. A pesquisa propõe assim, o desafio de trabalhar de maneira diferenciada e lúdica intercalando a sala de aula com os espaços não formais como o Museu de solo de Roraima.

É importante ressaltar que neste trabalho foi proposto o estudo do Museu de Solo de Roraima como espaço não formal de educação para as disciplinas de química e geografia. No entanto, enfatiza-se que este espaço pode ser explorado por várias outras disciplinas, como biologia, história, etc. ou até mesmo de maneira interdisciplinar. 


\section{REFERÊNCIAS}

BARDIN, L. Análise de conteúdo. São Paulo, SP: Edições 70, 2011.

BITTER, D. Museu como lugar de pesquisa. In: SALTO PARA O FUTURO. MUSEU E ESCOLA: EDUCAÇÃO FORMAL E NÃO-FORMAL, Anais [...] ano XIX., n. 3., maio/2009.

BRANDÃO, C. R. O que é educação?. São Paulo, SP: Brasiliense, 2004.

BRASIL. Base Nacional Comum Curricular - BNCC. Ensino Médio. Brasília: MEC, 2019.

CARBONELL, J. A aventura de inovar: a mudança na escola. Porto Alegre, RS: Artmed, (Coleção Inovação Pedagógica), 2002.

FALCÃO, A. Museu como lugar de memória. In: SALTO PARA O FUTURO. MUSEU E ESCOLA: EDUCAÇÃO FORMAL E NÃO-FORMAL, Anais [...] ano XIX., n. 3., maio/2009.

FRONZA-MARTINS, A. S. Da magia a sedução: a importância das atividades educativas não-formais realizadas em Museus de Arte. Revista de Educação, São Paulo, v. 9., n. 9., 2015.

GARCIA, V. A. Educação não formal do histórico ao trabalho local. In: PARK, M.; FERNANDES, R. S.; CARNICEL, A. (orgs.). Palavras-chave em educação não formal. Campinas, SP: Unicamp, CMU; Holambra: setembro, 2007.

GASPAR, A. Museus e centros de ciências: conceituação e proposta de um referencial teórico. Tese (Doutorado em Educação), Faculdade de Educação da Universidade de São Paulo, São Paulo, SP: USP, 1993.

GIL, A. C. Métodos e técnicas de pesquisa social. 6. ed. São Paulo, SP: Atlas, 2008.

GOHN, M. G. Educação não-formal e cultura política. Impactos sobre o Associativismo do Terceiro Setor. São Paulo, SP: Cortez, 2008.

HENDGES, A. P. Estágio não formal: vivenciando experiências com a Educação Especial. Revista Insignare Scientia - RIS, v. 2, n. 3, p. 21-30, 21 nov. 2019.

JACOBUCCI, D. F. C. Contribuições dos espaços não formais de educação para a formação da cultura científica. Revista Em extensão, Uberlândia, v. 7., 2008.

LIBÂNEO, J. C. Didática. São Paulo, SP: Cortez, (Coleção Magistério $2^{\circ}$ Grau. Série Formação do professor), 1994.

LIBÂNEO, J. C. Pedagogia e Pedagogos: para que?. São Paulo, SP: Cortez, 2002.

MARANDINO, M. et al. Educação em Museus: a mediação em foco. São Paulo, SP: GEENF/FEUSP, 2008. 
MARCONI, M. de A.; LAKATOS, E. M. Técnicas de pesquisa. 5. ed. São Paulo, SP: Atlas, 2006

MARQUES, F. A.; RIBEIRO, M. R.; LIMA, J. F. W. F.; JACOMINE, P. K. T.; CORRÊA, M. M. Procedimentos para coleta e preparo de perfis de solo preservados (macromonolitos). Rio de Janeiro, RJ: Embrapa Solos, 2011. Disponível em: <https://www.infoteca.cnptia.embrapa.br>. Acesso em: 10 dez. 2019.

PASSINI, E. Y.; PASSINI, R.; MALYSZ, S. T. (orgs.). Prática de ensino de geografia e estágio supervisionado. São Paulo, SP: Contexto, 2007.

RAMOS, M. F. Educação não formal: pedagogia social transformadora e motivadora. Brasil Escola. Pedagogia. 2019. Disponível em: <https://meuartigo.brasilescola.uol.com.br>. Acesso em: 10 dez. 2019.

RAMOS, P.; RAMOS, M. M.; BUSNELLO, S. J. Manual prático de metodologia da pesquisa: artigo, resenha, projeto, TCC, monografia, dissertação e tese. São Paulo, SP: Prentice, 2005.

REIGOTA, M. Meio Ambiente e Representação Social. 8. ed. São Paulo, SP: Cortez, 2010.

ROCHA, J. S.; VASCONCELOS, T. C. Dificuldades de aprendizagem no ensino de química: algumas reflexões. ENCONTRO NACIONAL DE ENSINO DE QUÍMICA, v. 18, p. 1-8, 2016.

SILVA FILHO, R. V. da.; PRAGANA, R. B.; NUNES, J. H. L.; SILVA, J. P. da. Confecção de minimonolitos de solo - uma ferramenta construtiva no ensino de ciência do solo. Revista Agrarian Academy, Centro Científico Conhecer - Goiânia, v. 6., n. 11., 2019. p. 353.

SILVA, L. N. A presença da Química nos Museus e Centros de Ciência do Rio de Janeiro. Dissertação (Mestrado em Ensino em Biociências e Saúde), Instituto Oswaldo Cruz, Rio de Janeiro, RJ: IOC/Fiocruz, 2015.

SOUSA, C. A. de.; MEDEIROS, M. C. S.; SILVA, J. A. L.; CABRAL, L. N. A aula de campo como instrumento facilitador da aprendizagem em Geografia no Ensino Fundamental. Revista Educação Pública. 2016. Disponível em: <https://educacaopublica.cecierj.edu.br>. Acesso em: 10 dez. 2019.

UFRR. Universidade Federal de Roraima. Museu de solos de Roraima: Objetivo e Histórico. Boa Vista, RR: UFRR - Campus Cauamé, 2019. Disponível em: <http://ufrr.br/museusolos>. Acesso em: 10 dez. 2019.

VALE JÚNIOR, I. F. Solos de Roraima. Revista Ação Ambiental, Belo Horizonte. v. 32., n. 1., p. 24- 27, 2005.

VIANNA, N.; RITTER, J. O que diz a literatura Brasileira em relação ao Currículo de Química. Revista Insignare Scientia - RIS, v. 2, n. 1, p. 33-49, 20 maio 2019. 
VIEIRA, V.; BIANCONI, M. L.; DIAS, M. Espaços não-formais de ensino e o currículo de ciências. Revista Ciência e Cultura, São Paulo, v. 57., n. 4., p. 21-23, 2005.

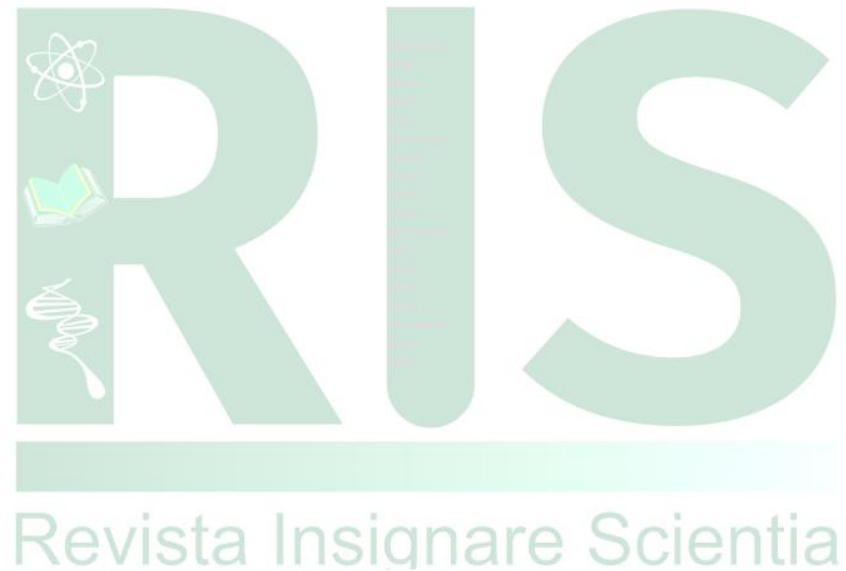

